\title{
Mathematical Modeling to Standardize Times in Assembly Processes: Application to Four Case Studies
}

\author{
Eliezer Colina (iD), Mario Peña (iD), Villie Morocho (D), Lorena Siguenza-Guzman (iD) \\ Universidad de Cuenca (Ecuador) \\ eliezrer.colina@ucuenca.edu.ec,mario.penao@ucuenca.edu.ec,villie.morocho@ucuenca.edu.ec, lorena.siguenza@ucuenca.edu.ec
}

Received: April 2020

Accepted: December 2020

\begin{abstract}
:
Purpose: This paper proposes model-based standard times estimates using multiple linear regression, non-linear optimization, and fuzzy systems in four real cases of assembly lines. The work includes a description of the models and compares their performance with measurements obtained through the conventional chronometer method. These models allow estimating standard times without reconducting field studies.
\end{abstract}

Design/methodology/approach: For the development of the time study, the methodology proposed by the International Labour Organization (ILO) was used as a baseline, which is structured in three phases: the selection of the case study, the registration of the process by direct observation, and the calculation/estimation of the standard time. The selected case studies belong to real assembly lines of motorcycles, television sets, printed circuit boards (PCB), and bicycles.

Findings: In the motorcycle's assembly case, the study allowed the construction of fourteen linear regression models: seven to estimate standard times for assembling the front parts and seven for the rear of the different motorcycle types. Compared to the conventional chronometer method, the results never exceeded $10 \%$ of the measured values. Regarding the cases of assembling TV sets and PCBs, the study considered the construction of nonlinear optimization models that allow making appropriate predictions of the standard times in their assembly lines. Finally, for the bicycle assembly line, a fuzzy logic model was constructed and validated to represent the standard time.

Research limitations/implications: To ensure the confidentiality of the companies used in the case study: all the names of the companies, services and the models of manufactured products are omitted.

Originality/value: The literature consulted does not refer to the representation of standard time on assembly lines using mathematical models. The construction of these models with empirical data from real-assembly lines was a valuable aid to the companies involved in supporting activity planning.

Keywords: assembly process, standard time, regression model, optimization model, fuzzy logic model

\section{To cite this article:}

Colina, E., Peña, M., Morocho, V., \& Siguenza-Guzman, L. (2021). Mathematical modeling to standardize times in assembly processes: Application to four case studies. Journal of Industrial Engineering and Management, 14(2), 294-310. https://doi.org/10.3926/jiem.3192 


\section{Introduction}

In the Small and Medium-sized Enterprises (SMEs) sector, companies with limited or non-standardized processes can be strengthened depending on their capacities to produce more, according to the demand for particular products in peak sales periods, by considering the competition from similar companies or, because of sudden circumstances such as changes in government policies. Planned growth of a company is possible through process standardization, aimed at improving production compliance rates and customer satisfaction (Shalley \& Gilson, 2017). To consolidate a company and be at the forefront of products or services, modern firms must consider competitiveness factors such as quality, delivery times, costs, and customer services, indicating a clear distinction in business performance (Yazdi, Azizi \& Hashemipour, 2019). Delivery times in production assembly lines influence business performance and, therefore, a time study represents an opportunity for higher productivity, reduction of production costs, and improvements in quality, which promote customer satisfaction (Munyai, Mbonyane, Mbohwa, Mbonyane \& Mbohwa, 2017). The standard time represents the time required by an average operator, or a machine, to perform a specified task within given conditions and a defined performance level.

Method Engineering encompasses approaches to increase productivity in industries. It allows optimizing resources, facilitating tools to raise competitiveness levels, and developing techniques focused on the study of work. It aims at solving problems in production processes, for example, by improving issues related to the inadequate administration of time and movement. A common feature in many assembly industries is relying on rigid models and using intensive capital in their production processes, making it costly to perform changes. Furthermore, the occurrence of disturbances may lead to works in process (WIP) or the creation of bottlenecks with severe consequences (Heizer, Render, \& Munson, 2016; Abdelkhak, Salama \& Eltawil, 2018). Another situation occurs in manufacturing by project, where each piece produced is different. Regardless of the case, it is necessary to be able to set standard times to optimize production.

Times study provides benefits to a company, such as increased commitment of operators, higher productivity levels, better quality and safety, improved efficiency in customer service, and error reduction in processes management. Additionally, it facilitates production planning based on standard times, reduction in production costs, and the possibility of establishing improvements in the assembly line that favor productivity (Nallusamy \& Muthamizhmaran, 2015). Two intimately related aspects are the study of methods and the time study (Chauhan, Kumar \& Shah, 2017). The study of methods allows for the analysis of operators' movements when executing tasks. It looks to improving them and to reduce operating times to a minimum (Munyai et al., 2017). On the other hand, the times study is based on measurements to determine optimal times in the execution of specific activities by trained operators (Maynard \& Hodson, 1992).

There are several studies conducted to improve the productivity in manufacturing processes and to increase the efficiency and effectiveness of organizations through time study (Al-Saleh, 2011; Bon \& Daim, 2010; Chandra, 2007; Elnekave \& Gilad, 2006; Hendrich, Chow, Skierczynski \& Lu, 2008; Kulkarni, Kshire \& Chandratre, 2015; Marri \& Shaikh, 2012; Patel, 2015). Various techniques are available to determine the standard time, $T_{S}$, associated with a process. Alternative procedures include estimates made by analysts, evaluation of historical records, use of a predetermined time system, and the times study with a chronometer. The estimates made by an analyst rely on expertise to determine $T_{S}$ adjusted to the activities under execution (Freivalds \& Niebel, 2013). The evaluation of $\mathrm{T}_{\mathrm{S}}$ by the technique of historical records depends on timed data of tasks performed in the past. One of the most advanced techniques for studying times corresponds to predetermined time systems, which allows ascertaining the value of $T_{S}$ through databases that contain information on movements and their respective durations (Munyai et al., 2017). The times study with a chronometer is the primary technique for measuring tasks. It is a direct method where the calculation of $\mathrm{T}_{\mathrm{S}}$ bases on the observation and timing of all process activities in a certain number of cycles (Meyers, 1992). The estimation of $\mathrm{T}_{\mathrm{S}}$ is also possible through formal approaches using mathematical models (Mundel, 1970).

Unlike other approaches, this article proposes the use of mathematical models to obtain $\mathrm{T}_{\mathrm{S}}$ estimates in four case studies of assembly lines and a comparison of results. The models' types come from a multiple linear regression structure, a nonlinear optimization frame, and a fuzzy logic construct. The work is organized as follows: Section 2 summarizes the conventional chronometer method used for measuring $T_{\mathrm{S}}$ in assembly lines. Section 3 presents the 
conceptual basis of the multiple linear regression structure, the nonlinear optimization frame, and the fuzzy logic construct proposed to estimate $T_{S}$ in assembly lines. Also, it contains a description of the considered case studies. Section 4 contemplates an analysis of results, where the performances of the mathematical models compare with the values of $T_{S}$ obtained with the chronometer method. The last section includes a discussion of general findings and conclusions.

\section{Conventional Chronometer Method for Standard Time Measurement}

The chronometer time study is a reliable method which provides sufficient accuracy and requires establishing a minimum number, $N$, of observations. Freivalds and Niebel (2013) presented a method of calculating $N$ based on a number $n$ of observations previously made. This calculation is through Equation (1), using the standard deviation $\sigma$ given by Equation (2).

$$
\begin{gathered}
N=\left(\frac{k \cdot \sigma}{\epsilon \cdot \bar{T}}\right)^{2} \\
\sigma=\sqrt{\frac{\sum_{i=1}^{n}\left(T_{i}-\bar{T}\right)^{2}}{n}}
\end{gathered}
$$

Where $k$ represents the risk coefficient, whose value is $k=1$ for risk error of $32 \%, k=2$ for risk error of $5 \%$, and $k=3$ for risk error $0.3 \%$; e symbolizes the error, expressed in decimal form; $T_{i}$ corresponds to the $i$-th measurement of time using the chronometer; and $\bar{T}$ is the arithmetic mean of the time measurements, calculated using Equation (3).

$$
\bar{T}=\frac{\sum_{i=1}^{n} T_{i}}{n}
$$

Alternatively, the value of $N$ is available using the Westinghouse table generated by the General Electric methodology, which provides the number of observations based on the time measured in the process cycle (Meyers \& Stewart, 2001).

Once calculated the number of observations, it proceeds to determine the total activity time average $\bar{T}_{a}$, using Equation (4), and the calculation of the normal time $T_{N}$, given by Equation (5). The value of $T_{N}$ depends on the parameter " $\%$ valuation" that corresponds to the valuation of the Westinghouse system, which takes into consideration four elements related to the work rate. These elements are skill, effort, conditions, and consistency (Freivalds \& Niebel, 2013).

$$
\begin{gathered}
\bar{T}_{a}=\frac{\sum_{l=1}^{N} T_{i}}{N} \\
T_{N}=\bar{T}_{a} \cdot(\% \text { valuation })
\end{gathered}
$$

Finally, the calculation of $T_{S}$ is done with Equation (6), which includes a term called "supplements" to amalgamate general factors such as work conditions, environment, and gender, breaks to recover from fatigue, and physiological needs, among other aspects (Meyers \& Stewart, 2001).

$$
T s=T_{N} \cdot(1+\text { supplements })
$$

Models associated with assembly lines can also be grouped using the analysis of variance (ANOVA) by comparing mean values to determine if any of them differ significantly from others. The relationship stipulated in (7) provides a statistical value $F . F$ is calculated by dividing the estimate of the group variations of the independent variable with " $g-1$ " degrees of freedom and the estimation of the group variations with " $n-g "$ degrees of freedom (Turner \& Thayer, 2001). 


$$
\left[\frac{\text { Variation } g-1}{\text { Variación }_{n-g}}\right] \approx F_{g-1, n-g}
$$

If $\quad F>F_{g-1, n-g} \rightarrow H_{1}$ (There are differences among models)

If $F>F_{g-1, n g} \rightarrow H_{0}$ (There are no differences among models)

The result obtained from relation (7) is compared with the tables of the $F$ distribution proposed by Moore and McCabe (1998), taking into account a level of significance of at least $5 \%$ to accept the null hypothesis of equality among groups, as stipulated in (8).

\section{Mathematical Models to Estimate the Standard Time}

The construction of empirical mathematical models leads to establishing the statistically significant relationships between variables in a specific context of measurements and for a particular purpose. These relationships can be static or dynamic and allow, for example, approximating the behavior of a process. It provides estimates or predictions of the value assumed by its dependent variables in terms of the values of its independent variables. In this way, the mathematical models lead to systematizing the information contained in the data and serve as a backup to decision-making tasks.

There are several ways to build empirical mathematical models to represent the same process. In any case, a model must be able to represent reality by satisfying objectives such as description, explanation, optimization, or even more, serving as the basis to affect it. The considered models of multiple linear regression, non-linear optimization, and fuzzy logic, given they are of the input-output type, only represent variations of the dependent variable (output of the process) before changes in the values of the independent variables (inputs of the process).

\subsection{Multiple Linear Regression Model to Estimate the Standard Time}

The foundations related to the construction of a multiple linear regression model include the formulation of a hypothesis, which linearly links the output of the process with a set of independent variables, of which measurements are available, and the definition of an objective function. In this sense, Equation (9) represents the hypothesis.

$$
h_{\beta}(x)=\beta^{T} x
$$

The value of $h_{\beta}(x)$ symbolizes the prediction of the standard time. It assumes that the contribution of each independent variable to the estimated standard time is weighted by a constant value. The elements of the vector $\beta$, given in Equation (10), correspond to constant values to be determined. The array $x$ represents the vector of input variables presented in Equation (11), which must be selected appropriately. The subscript $p$ indicates the number of independent variables present in the hypothesis. The objective function $J(\beta)$, given by Equation (12), takes into account the quadratic deviations between the hypothesis and the standard times measured using the conventional chronometer method. Its minimization yields the parameters of the vector $\beta$.

The concatenation of the measurements of the input variables, arranged in the vector $x^{(i)}$, defined in Equation (13), allows constructing the design matrix $X$, given by Equation (14). Finally, the measurements of the output variable allow defining the vector $T_{S}$, presented in Equation (15).

$$
\begin{gathered}
\beta=\left(\beta_{0}, \beta_{1}, \beta_{2}, \ldots, \beta_{p}\right)^{T} \\
\mathrm{x}=\left(1, x_{1}, x_{2}, \ldots, x_{p}\right)^{T} \\
I(\beta)=\frac{1}{2 m} \sum_{i=1}^{m}\left(h_{\beta}\left(x^{(i)}\right)-T_{S}^{(i)}\right)^{2}
\end{gathered}
$$




$$
\begin{gathered}
\mathrm{x}^{(i)}=\left(1, x_{1}^{(i)}, x_{2}^{(i)}, \ldots, x_{p}^{(i)}\right)^{T} ; i=1,2, \ldots, m \\
X=\left[\begin{array}{c}
\left(x^{(1)}\right)^{T} \\
\left(x^{(2)}\right)^{T} \\
\vdots \\
\left(x^{(m)}\right)^{T}
\end{array}\right] \\
T_{S}=\left(T_{S}^{(1)}, T_{S}^{(2)}, \ldots, T_{S}^{(\mathrm{m})}\right)^{T}
\end{gathered}
$$

Equation (16) represents the solution to minimizing the objective function $J(\beta)$ (Ramirez, Guaman, Colina-Morles \& Siguenza-Guzman, 2020).

$$
\beta=\left(X^{T} X\right)^{-1} X^{T} T_{S}
$$

The linear correlation coefficient $r^{2}$, defined in Equation (17), allows identifying the influence that an input variable exerts on the output variable. Its value belongs to the interval $[-1,1]$, and it represents a measure of how good the fit of the linear regression hypothesis is, compared to the measurements. If the value equals 1 , then an exact linear relationship exists between an input variable and the output variable $T_{s}$.

$$
r^{2}=\frac{s_{x_{i} T_{S}}^{2}}{S_{x_{i}}^{2} S_{T_{S}}^{2}}
$$

Where $S^{2}{ }_{x i T s}$ is the covariance between $x_{i}$ and $T_{S} . S^{2}{ }_{x i}$ symbolizes the standard deviation of $x_{i}$, and $S^{2}{ }_{T s}$ corresponds to the standard deviation of $T_{S}$.

\subsubsection{Case Study 1: Application to a Motorcycle Assembly Line}

The study considered variables related to the work environment and operators of an assembly plant that produces seven different models of motorcycles, coded as M1, M2, M3, M4, M5, M6, M7, and consists of six assembly cells. Two operators work in each cell and perform simultaneous tasks, both in the front and the rear of the motorcycle, allowing the correct assembly of each product.

To construct a multiple linear regression model to predict the standard time, it is necessary to select those variables that influence its determination. From Equation (17), it is necessary to analyze the values of the correlation coefficients of each independent variable concerning the standard time (Montgomery, Peck \& Vining, 2013). Five independent variables resulted from this analysis. They were age, weight, height, noise, and illumination. For example, taking the rear of the M7 model as a base process, Table 1 includes the values of the correlation coefficient for the independent variables selected. Note that the variables illumination and noise are the most correlated with standard time. Next, there come the variables age and weight; finally, height affects only $8.1 \%$ on the standard time estimation.

Corresponding to the assembly of the front of the motorcycles, Table 2 shows the selected variables and their measured values. In addition, Table 3 collects the information for the assembly process of the rear of the motorcycles.

\begin{tabular}{|c|r|r|r|r|r|}
\hline Variable $\boldsymbol{x}_{\boldsymbol{i}}$ & \multicolumn{1}{|c|}{ Age (year) } & Weight $(\mathrm{kg})$ & \multicolumn{1}{|c|}{ Height $(\mathrm{cm})$} & \multicolumn{1}{c|}{ Noise (db) } & \multicolumn{1}{c|}{ Illumina. (lux) } \\
\hline Coef. $r^{2}$ & 0.137216 & 0.123469 & 0.081088 & 0.261844 & 0.397216 \\
\hline
\end{tabular}

Table 1. Correlation values between independent and dependent variables 


\begin{tabular}{|l|r|r|r|r|r|r|}
\hline \multicolumn{1}{|c|}{ Variable } & Cell 1 & Cell 2 & Cell 3 & Cell 4 & Cell 5 & Cell 6 \\
\hline Age (year) & 38 & 33 & 21 & 19 & 22 & 27 \\
\hline Weight (kg) & 61 & 63 & 54 & 66 & 66 & 63 \\
\hline Height (cm) & 160 & 165 & 164 & 176 & 165 & 165 \\
\hline Noise (db) & 90 & 94 & 88 & 178 & 93 & 91 \\
\hline Illumina. (lux) & 194 & 187 & 214 & 189 & 194 \\
\hline
\end{tabular}

Table 2. Values of independent variables from the front of motorcycles

\begin{tabular}{|l|r|r|r|r|r|r|}
\hline Variable & Cell 1 & Cell 2 & Cell 3 & Cell 4 & Cell 5 & Cell 6 \\
\hline Age (year) & 38 & 28 & 30 & 24 & 23 & 23 \\
\hline Weight (kg) & 54 & 66 & 54 & 56 & 68 & 62 \\
\hline Height (cm) & 160 & 175 & 160 & 171 & 163 & 168 \\
\hline Noise (db) & 90 & 94 & 88 & 178 & 93 & 91 \\
\hline Illumina. (lux) & 194 & 187 & 214 & 189 & 194 \\
\hline
\end{tabular}

Table 3. Values of independent variables from the rear of motorcycles

Equation (18) results from matching the right side of Equation (9) with the dependent variable estimated standard time $T_{S e}$.

$$
T_{S e}^{l}=\left(\beta^{T}\right)^{l} x ; \quad 1=1,2, \ldots, 7
$$

Where $\beta=\left(\beta_{0}^{l}, \beta_{1}^{l}, \ldots, \beta_{5}{ }^{\prime}\right)^{T}$ and $x=\left(1, x_{1}, \ldots, x_{5}\right)^{T}$.

The elements of the vector $\beta$ result from minimizing the cost function given by Equation (19).

$$
J(\beta)_{l}=\frac{1}{2 m} \sum_{i=1}^{m}\left(T_{S \theta}^{l}{ }^{(i)}-T_{S}^{(i)}\right)^{2} ; \quad l=1,2, \ldots, 7
$$

The observed values were determined following the conventional chronometer method for measuring the standard time, as described in Section 3. For illustrative purposes, Table 4 includes a record of observed times in minutes, for the assembly of the rears of the seven motorcycle models in cell 1. On the other hand, Table 5 and Table 6 contain the values of standard times calculated with Equation (6) for both the front and the rear processes. It includes all assembly cells and the seven motorcycle models.

\begin{tabular}{|c|r|r|r|r|r|r|}
\hline \multirow{2}{*}{ Motorcycle model } & \multicolumn{7}{|c|}{ Observed time (min.s) } & \multicolumn{2}{|c|}{ Average time } \\
\cline { 2 - 7 } & 1 & 2 & 3 & 4 & 70.8 & 70.13 \\
\hline M1 & 70.19 & 70.2 & 69.58 & 70.37 & 78.34 & 77.35 \\
\hline M2 & 78.23 & 77.28 & 75.37 & 77.53 & 52.17 & 52.51 \\
\hline M3 & 54.11 & 52.28 & 52.25 & 52.53 & 47.8 & 48.49 \\
\hline M4 & 49.00 & 49.11 & 49.11 & 49.36 & 58.31 & 58.26 \\
\hline M5 & 59.55 & 57.00 & 59.57 & 56.48 & 57.43 & 57.25 \\
\hline M6 & 57.29 & 57.32 & 57.44 & 56.39 & 64.50 & 64.55 \\
\hline M7 & 66.40 & 64.5 & 63.59 & 64.58 & 64.50 & \\
\hline
\end{tabular}

Table 4. Observed times for assembly rear of motorcycles, cell 1 


\begin{tabular}{|c|r|r|r|r|r|r|}
\hline Motorcycle & \multicolumn{1}{|c|}{ Cell 1 } & Cell 2 & \multicolumn{1}{c|}{ Cell 3 } & \multicolumn{1}{c|}{ Cell 4 } & \multicolumn{1}{c|}{ Cell 5 } & 70.8 \\
\hline M1 & 70.19 & 70.2 & 69.58 & 70.37 & 77.13 \\
\hline M2 & 78.23 & 77.28 & 75.37 & 53 & 78.34 & 77.35 \\
\hline M3 & 54.11 & 52.28 & 52.25 & 52.53 & 52.17 & 52.51 \\
\hline M4 & 49.00 & 49.11 & 49.11 & 49.36 & 47.8 & 48.49 \\
\hline M5 & 59.55 & 57.00 & 59.57 & 56.48 & 58.31 & 58.26 \\
\hline M6 & 57.29 & 57.32 & 57.44 & 56.39 & 57.43 & 57.25 \\
\hline M7 & 66.40 & 64.5 & 63.59 & 64.58 & 64.50 & 64.55 \\
\hline
\end{tabular}

Table 5. Standard time $T_{S}$ for the front of motorcycles [min]

\begin{tabular}{|c|c|c|c|c|c|c|}
\hline Motorcycle & Cell 1 & Cell 2 & Cell 3 & Cell 4 & Cell 5 & Cell 6 \\
\hline M1 & 95.49 & 92.68 & 88.12 & 93.89 & 89.94 & 90.57 \\
\hline M2 & 107.12 & 105.65 & 99.17 & 107.47 & 100.31 & 102.62 \\
\hline M3 & 72.54 & 74.70 & 66.44 & 69.95 & 67.83 & 68.10 \\
\hline M4 & 67.41 & 66.91 & 62.59 & 65.72 & 63.42 & 64.86 \\
\hline M5 & 80.68 & 80.02 & 72.64 & 78.62 & 77.38 & 76.72 \\
\hline M6 & 79.27 & 77.66 & 73.18 & 78.54 & 75.00 & 75.30 \\
\hline M7 & 83.26 & 78.88 & 76.38 & 82.45 & 78.53 & 78.86 \\
\hline
\end{tabular}

Table 6. Standard time $T_{S}$ for the rear of motorcycles [min]

The minimization of the objective function given by Equation (19) for the assembly processes in the front and rear parts of each motorcycle model, leads to the multiple linear regression models given in Tables 7 and 8.

\begin{tabular}{|c|c|}
\hline Motorcycle & Standard time estimation model \\
\hline M1 & $T_{S e}{ }^{1}=815.92-1.16 x_{1}-2.29 x_{2}-1.87 x_{3}-0.25 x_{4}-1.17 x_{5}$ \\
\hline M2 & $T_{S e}{ }^{2}=660.91-0.78 x_{1}-1.65 x_{2}-1.45 x_{3}-0.03 x_{4}-1.07 x_{5}$ \\
\hline M3 & $T_{S e}{ }^{3}=921.05-1.17 x_{1}-2.29 x_{2}-1.98 x_{3}-0.10 x_{4}-1.51 x_{5}$ \\
\hline M4 & $T_{S_{e}}{ }^{4}=592.12-0.59 x_{1}-1.85 x_{2}-1.15 x_{3}-0.58 x_{4}-0.81 x_{5}$ \\
\hline M5 & $T_{S e}{ }^{5}=722.91-0.96 x_{1}-2.31 x_{2}-1.51 x_{3}-0.09 x_{4}-1.14 x_{5}$ \\
\hline M6 & $T_{S e}{ }^{6}=957.91-1.28 x_{1}-2.46 x_{2}-2.24 x_{3}-0.77 x_{4}-1.36 x_{5}$ \\
\hline M7 & $T_{S e}{ }^{7}=885.64-1.23 x_{1}-2.50 x_{2}-2.01 x_{3}-0.19 x_{4}-1.36 x_{5}$ \\
\hline
\end{tabular}

Table 7. Multiple linear regression models for the front of motorcycles

\begin{tabular}{|c|c|}
\hline Motorcycle & Standard time estimation model \\
\hline M1 & $T_{S_{e}}{ }^{1}=88.19-0.23 x_{1}-1.18 x_{2}-0.10 x_{3}-1.95 x_{4}-0.41 x_{5}$ \\
\hline M2 & $T_{S_{e}}{ }^{2}=66.29-0.56 x_{1}-1.99 x_{2}-0.03 x_{3}+3.25 x_{4}-0.61 x_{5}$ \\
\hline M3 & $T_{S_{e}}{ }^{3}=-16.77+0.07 x_{1}-0.85 x_{2}+0.17 x_{3}+1.95 x_{4}-0.37 x_{5}$ \\
\hline M4 & $T_{S_{e}}{ }^{4}=0.65-0.56 x_{1}-1.68 x_{2}-0.08 x_{3}+3.05 x_{4}-0.43 x_{5}$ \\
\hline M5 & $T_{S_{e}}{ }^{2}=54.04-0.23 x_{1}-1.08 x_{2}-0.12 x_{3}+2.19 x_{4}-0.43 x_{5}$ \\
\hline M6 & $T_{S_{e}}{ }^{6}=77.58-0.07 x_{1}-0.75 x_{2}-0.03 x_{3}+1.24 x_{4}-0.32 x_{5}$ \\
\hline M7 & $T_{S_{e}}{ }^{7}=120.62-0.23 x_{1}-0.94 x_{2}-0.20 x_{3}+1.32 x_{4}-0.34 x_{5}$ \\
\hline
\end{tabular}

Table 8. Multiple linear regression models for the rear of motorcycles 


\subsection{Non-Linear Optimization Model to Estimate the Standard Time.}

In many cases, given the requirement to assemble different products, time measurements associated with process activities do not have a regular pattern that suggests a representable behavior using a single linear model. In these circumstances, the hypothesis to estimate the standard times can be written in a general way using Equation (20).

$$
T_{W e}=h_{\beta}(x)
$$

Where the structure of $h_{\beta}(x)$ depends on the process to model. The elements of $\beta$ correspond to parameters to determine, and $x$ represents a set of variables to select appropriately.

The minimization of the objective function given by Equation (21) yields the parameter $\beta_{i}$. In this work, the objective function is a normalized version of the standard deviation $S$ that measures the variations of the estimated standard time values respect to the mean cycle time (Guerrero, Guaman, Colina Morles, \& Siguenza-Guzman, 2020).

$$
S=\sqrt[2]{\frac{\sum_{i=1}^{N} \theta_{i}^{2}}{N}}
$$

Note that Equation (22) defines the error $e_{i}$. Here, the mean cycle time $\bar{T}_{c}$ is given by Equation (23). $N$ represents the number of observations.

$$
\begin{aligned}
& e_{i}=\frac{T_{E e_{i}}-\bar{T}_{C}}{\bar{T}_{c}} \\
& \bar{T}_{c}=\frac{\sum_{i=1}^{N} T_{c i}}{N}
\end{aligned}
$$

Finally, the estimation model must take into account the physical constraint given by Equation (24), which imposes a value of $T_{E \mathrm{Ee}}$ higher than or equal to $\bar{T}_{c}$.

$$
T_{E e} \geq \bar{T}_{c} T_{E e} \geq \bar{T}_{c}
$$

Case studies 2 and 3. The assembly of television sets (TV) and printed circuit boards (PCB).

There is a company that manually assembles eight different TV types, identified as TV1, TV2, TV3, TV4, TV5, TV6, TV7, TV8. The company also assembles three PCBs, identified as PCB1, PCB2, and PCB3 in an automated manner and one PCB, identified as PCB4 in semi-automated means. To undertake improvements, the company decided to model its processes to support planning, control, use of materials, machinery, and labour.

Before the construction of mathematical models to estimate standard times, taking into account the relationships (7) and (8) and the tables of the F distribution, the ANOVA allows determining which TV types, and PCB types, can be grouped under the same mathematical model. Table 9 and Table 10 illustrate the ANOVA results, which show that with a level of significance of $6.6 \%$, the types TV3, TV4, and TV5 form a group. The types TV6 and TV8 form a different group, and each of the remaining three types, TV1, TV2, and TV7, constitute individual groups. Additionally, Table 11 and Table 12 reflect that since a grouping with a level of significance higher than 5\% is not possible, the four types of PCBs constitute separate groups.

\begin{tabular}{|c|r|r|r|}
\hline Groups & \multicolumn{2}{|c|}{ Sum } & \multicolumn{1}{c|}{ Average } \\
\hline TV3 & 141.4243567 & 9.4282904 & 0.028721239 \\
\hline TV4 & 143.3322788 & 9.5554853 & 0.010714174 \\
\hline TV5 & 142.2510037 & 9.4834002 & 0.023953983 \\
\hline
\end{tabular}

Table 9. ANOVA summary. Television sets assembly case 


\begin{tabular}{|l|r|r|r|r|r|r|}
\hline \multicolumn{1}{|c|}{ Variation } & Square sum & Degrees of freedom & Square average & F & Probab & Critical value F \\
\hline Among groups & 0.1221 & 2 & 0.0610 & 2,8883 & 0,0668 & 3.2199 \\
\hline Inside groups & 0.8874 & 42 & 0.0211 & & & \\
\hline Total & 1.0095 & 44 & & & & \\
\hline
\end{tabular}

Table 10. Variance analysis. Television sets assembly case

\begin{tabular}{|c|c|c|c|}
\hline Groups & Sum & Average & Variance \\
\hline PCB1 & 3752.265821 & 375.22658 & 0.187901602 \\
\hline PCB2 & 4433.751352 & 443.37514 & 0.055468132 \\
\hline PCB3 & 4767.084685 & 476.70847 & 0.055468132 \\
\hline PCB4 & 5517.084685 & 551.70847 & 0.055468132 \\
\hline
\end{tabular}

Table 11. ANOVA summary. Printed circuit boards case

\begin{tabular}{|l|r|r|r|r|r|r|}
\hline \multicolumn{1}{|c|}{ Variation } & Square sum & Degrees of freedom & Square average & F & Probab & Critical value F \\
\hline Among groups & 161402.1 & 3 & 53800.7 & 607392.8 & $1.02 \mathrm{E}-84$ & 2,8662 \\
\hline Inside groups & 3.1887 & 36 & 0.0885 & & & \\
\hline Total & 161405.3 & 39 & & & & \\
\hline
\end{tabular}

Table 12. Variance analysis. Printed circuit boards case

The previous analysis and Equation (20) lead to formulating a hypothesis to estimate standard times, in terms of the mathematical model described by Equation (25). $\beta_{i}$ and $\lambda$ are parameters to determine appropriately.

$$
h_{\beta}(\mathrm{x})=T_{E e}+\beta_{0}+\lambda \beta_{1} x_{1}+(1-\lambda) \beta_{2} x_{2}+\beta_{3} x_{3}
$$

For the group composed of TV3, TV4, and TV5, the value of $\beta_{1}$ equals $\beta_{2}$; the binary parameter $\lambda$ takes the value 1 for TV with a curved screen and takes the value 0 for TV with a flat-screen. The variable $x_{1}$ expresses the product of the Westinghouse rating and the number of screws used to assemble curved screen TV. The variable $x_{2}$ symbolizes the product of the Westinghouse rating and the number of screws used to assemble flat-screen TV. Finally, the variable $x_{3}$ represents the product of supplements and the number of operators.

For the group formed by TV6 and TV8, the value of $\beta_{1}$ equals $\beta_{2}$; the binary parameter $\lambda$ is 0 for TV assembled in a production cell, and 1 for TV assembled in a production line. The variable $x_{1}$ is the product of the Westinghouse rating, the number of screws, and the number of nut-bolt joints used for assembling within a production line. The variable $x_{2}$ denotes the product of the Westinghouse rating, the number of screws, and the number of nut-bolt connections used within a production cell. Finally, the variable $x_{3}$ represents the product of supplements and the number of operators.

TV1, TV2, and TV7 correspond to different mathematical models, and the value of the binary parameter $\lambda$ is always 1. For the four PCB types, which correspond with different mathematical models, the value of $\lambda$ always equals 1 . The variable $x_{1}$ is the sum of the Westinghouse System ratings for the packaging and storage processes of the automated line. The variable $x_{3}$ is the sum of supplements for the packaging, quality test, and storage processes of the automated line.

Table 13 presents the non-linear optimization models constructed to estimate standard times in the assembly of the eight TV types. In addition, Table 14 contains the optimization models constructed to estimate standard times in the assembly of the four PCB types. 


\begin{tabular}{|c|c|}
\hline TV type & Standard time estimation model \\
\hline TV3, TV4, TV5 & $T_{E e}=94833107+0.095466 x_{1}-0.2367265 x_{3}$ \\
\hline TV6, TV8 & $T_{E e}=451821937-19369034 x_{2}-36630928 x_{3}$ \\
\hline TV1 & $T_{E e}=125365812+150068026 x_{2}-77344491 x_{3}$ \\
\hline TV2 & $T_{E e}=-41182778+12349628 x_{2}+523590014 x_{3}$ \\
\hline TV7 & $T_{E e}=208426902-2477528161 x_{2}-3082434 x_{3}$ \\
\hline
\end{tabular}

Table 13. Non-linear optimization models to estimate standard times. Case study: TV set assembly

\begin{tabular}{|c|c|}
\hline Printed circuit board type & Standard time estimation model \\
\hline PCB1 & $T_{E e}=11931085+13362835 x_{1}+287539354 x_{3}$ \\
\hline PCB2 & $T_{E e}=-8520685+4492499 x_{1}+10856,86 x_{3}$ \\
\hline PCB3 & $T_{E e}=4039,05-66,03 x_{1}-5826,14 x_{3}$ \\
\hline PCB4 & $T_{E e}=526391645+806130518 x_{1}-34444452 x_{3}$ \\
\hline
\end{tabular}

Table 14. Non-linear optimization models to estimate standard times. Case study: PCB assembly

\subsection{Fuzzy Modeling to Estimate the Standard Time}

The study of times in a production process involves imprecisions due to variability in the data. In turn, this depends on instruments measurement imprecisions and, possibly, to human subjectivity (Morillas, 2014; Silva, 2018).

Fuzzy logic connotes a systematic approach for modeling processes where degrees of uncertainty affect the values of the involved variables (Zohoori, Verbraeck, Bagherpour \& Khakdaman, 2019). For the case study considered, once identified the sub-processes, variables of interest, and physical constraints influencing execution times of activities, there proceeds to obtain measurements of minimum times $\left(T_{\text {minin }}\right)$ and maximum times $\left(T_{\max }\right)$ of the sub-processes with a chronometer. Within the assembly processes, these times vary due to factors such as observation errors, operator changes, working conditions changes, transport delays, and matrices changes in machinery, among others. Under these circumstances, this work proposes the fuzzification of the variables, characterizing them with fuzzy labels, and the construction of a -type fuzzy model to estimate the standard times $\left(T_{E e}\right)$ associated with the operating conditions of the processes. Next, there is a description of the general structure of the proposed fuzzy model.

The model input and output variables are fuzzy representations of the times $T_{A}, T_{B}, T_{G} \ldots, T_{J}$, and $T_{E e}$ associated with the assembly sub-processes, identified with A, B, C, ..., J, and with the standard time estimated. These representations correspond to triangular functions $f\left(x, a_{i}, b_{i}, c_{i}\right)$ and trapezoidal functions $f\left(x, b_{i}, c_{i}, d_{i}\right)$, as described in Equation (26) and Equation (27) (Garibaldi \& Ozen 2007). The value of the output variable $T_{E e}$ for an assembly line results from the defuzzification of the fuzzy output set of the model for the particular operating conditions of its sub-processes.

$$
\begin{array}{r}
f\left(x, a_{i}, b_{i}, c_{i}\right)=\left\{\begin{array}{lr}
1 & \text { for } a_{i} \leq x \leq b_{i} \\
\frac{x-b_{i}}{c_{i}-b_{i}} & \text { for } b_{i} \leq x \leq c_{i} \\
0 & \text { for } x>c_{i}
\end{array}\right. \\
g\left(x, b_{i}, c_{i}, d_{i}\right)=\left\{\begin{array}{cc}
0 & \text { for } x<b_{i} \\
\frac{b_{i}-x}{c_{i}-b_{i}} & \text { for } b_{i} \leq x \leq c_{i} \\
1 & \text { for } c_{i} \leq x \leq d_{i}
\end{array}\right.
\end{array}
$$

The structure of the linguistic statements of the Mamdani-type model to estimate standard times is of the form described in (28). 
(u) If $T_{A}$ is $T_{A s}$ and $T_{B}$ is $T_{B s}$ and $T_{C}$ and $T_{C}$ is $T_{C s}$ and $\ldots$ and $T_{J}$ is $T_{J s}$ then $T_{E e}$ is $T_{E e s}$

also

...

also

(y) If $T_{A}$ is $T_{A l}$ and $T_{B}$ is $T_{B l}$ and $T_{C}$ is $T_{C l}$ and $\ldots$ and $T_{J}$ is $T_{J l}$ then $T_{E e}$ is $T_{E e l}$

The parameters $a_{i}, b_{i}, c_{i}$ and $d_{i}$ of Equation (26) and Equation (27) correspond to known values that characterize the times associated with the linguistic labels $T_{A s}, T_{A l}, T_{B s}, T_{B s}, T_{B l}, \ldots, T_{J s}, T_{J l}, T_{E e s}, T_{E e m}$ and $T_{e e l}$ present in the fuzzy statements $(u)$ and $(y)$, given in (28). For the input variables, these linguistic labels are the fuzzy sets "small" $(s)$ and "large" $(l)$. For example, $T_{A s}$ symbolizes "small-time" of subprocess A. For the output variable of each statement, in addition to the two mentioned fuzzy sets, there is the fuzzy set "medium" $(m)$. For example, $T_{E e m}$ symbolizes "medium standard time estimated".

The fuzzy reasoning engine used will interpret the "and" term, as well as the "then" implication within each statement, as an interception of fuzzy sets implemented in terms of the minimum operator. The connector "also" between statements performs the union of fuzzy sets, implemented as the maximum operator. The defuzzification of the output set is with the centroid method (Rodas, Guaman, Colina Morles, Peña \& Siguenza-Guzman, 2019).

\subsubsection{Case Study: Application to a Bicycle Assembler}

A company assembles twelve different models of bicycles, coded as $1 \mathrm{~A}, 1 \mathrm{~B}, 2 \mathrm{~A}, 3 \mathrm{~A}, 3 \mathrm{~B}, 3 \mathrm{C}, 3 \mathrm{D}, 3 \mathrm{E}, 3 \mathrm{~F}, 3 \mathrm{G}, 3 \mathrm{H}$, and 4A. The production involves sub-processes composed of different activities performed by operators. To carry out a detailed analysis of the assembly process, fifteen measurements of time were taken for each activity using the chronometer method.

There were records of the minimum and maximum times to undertake the ten sub-processes associated with the production of each model. For illustrative purposes, Table 15 contains measured time values of the sub-processes for two bicycle models. Times are in minutes and seconds; for example, 158.2 represents 158 minutes and 20 seconds. The associated sub-processes are the following: $\mathrm{A}=$ Cut, $\mathrm{B}=$ Forming, $\mathrm{C}=$ Weld, $\mathrm{D}=$ Painting, $\mathrm{E}=$ Assembly of the complete frame, $\mathrm{F}=$ Assembly of rims, $\mathrm{G}=$ Assembly rudder, $\mathrm{H}=$ Assembly of accessories, $\mathrm{I}=$ Assembly of the saddle and $\mathrm{J}=$ Storage of finished product.

The production plan of the company includes 500 units of two bicycle models per week. The company operates five days a week, in a single shift of eight hours. The first row of Table 16 indicates the planned production fulfilment periods, where each sub-process should not exceed the assigned day limits to avoid the accumulation of inventories. In addition, the second row of Table 16 indicates the number of operators per sub-process.

The setup times in each process correspond to the preparation of materials and transport. In some cases, it includes the calibration and matrix change of each machine. The measurements include them all. The conventional chronometer method described in Section 2 allows performing the standard time calculations, and the General Electric table supports determining the number of cycles to measure (Rodas et al., 2019). Table 17 summarizes the results obtained.

\begin{tabular}{|c|c|c|c|c|c|c|c|c|c|c|c|}
\hline Model & Times & A & B & C & $\mathrm{D}$ & $\mathrm{E}$ & $\mathrm{F}$ & G & $\mathrm{H}$ & I & $\mathrm{J}$ \\
\hline \multirow{2}{*}{$1 \mathrm{~A}$} & $T_{\min }$ & 0.54 & 2.07 & 6.24 & 158.20 & 1.16 & 2.23 & 0.51 & 0.52 & 4.46 & 0.16 \\
\hline & $T_{\max }$ & 1.58 & 2.17 & 8.14 & 158.40 & 2.18 & 2.58 & 0.58 & 1.09 & 6.22 & 0.20 \\
\hline \multirow{2}{*}{$2 \mathrm{~A}$} & $T_{\min }$ & 0.24 & 1.14 & 16.01 & 99.20 & 3.37 & 5.3 & 0.55 & 3.16 & 5.07 & 0.28 \\
\hline & $T_{\max }$ & 0.27 & 1.39 & 17.52 & 100.10 & 4.41 & 9.28 & 1.22 & 3.46 & 6.42 & 0.55 \\
\hline
\end{tabular}

Table 15. Minimum and maximum times for sub-processes of two bicycle models 


\begin{tabular}{|c|r|r|r|r|r|r|r|r|r|r|}
\hline Sub-process & A & B & C & D & E & F & G & H & I & J \\
\hline Day limits & $1 / 2$ & 1 & 3 & 3 & 3 & 3 & 2 & 3 & 2 & 1 \\
\hline Operators & 1 & 2 & 12 & 2 & 3 & 5 & 1 & 3 & 1 & 1 \\
\hline
\end{tabular}

Table 16. Limit of days per sub-process

\begin{tabular}{|c|c|c|c|c|c|c|}
\hline Model & $1 \mathrm{~A}$ & $1 \mathrm{~B}$ & $2 \mathrm{~A}$ & $3 \mathrm{~A}$ & $3 \mathrm{~B}$ & $3 \mathrm{C}$ \\
\hline$T_{E}$ & 410.06 & 359.45 & 395.12 & 444.46 & 492.5 & 430.58 \\
\hline Model & $3 \mathrm{D}$ & $3 \mathrm{E}$ & $3 \mathrm{~F}$ & $3 G$ & $3 \mathrm{H}$ & $4 \mathrm{~A}$ \\
\hline$T_{E}$ & 489.31 & 402.5 & 552.34 & 552.04 & 459.28 & 362.16 \\
\hline
\end{tabular}

Table 17. Standard times obtained by the conventional chronometer method

The linguistic labels "small" $(s)$ and "large" $(l)$ characterize the fuzzy input variables within the range of values that define their universes of discourses. For example, regarding the assembly of bicycle model 1A, the linguistic labels "Time of sub-process A small" $\left(T_{A s}\right)$ and "Time of sub-process A large " $\left(T_{A l}\right)$, illustrated in Figure 1a, represent the fuzzy input variable "Time of sub-process A". The universe of discourse of this variable is the time interval $[0.54,1.58]$. The trapezoidal membership functions of the fuzzy sets correspond to $\mu_{\mathrm{TA}}$. The fuzzification of the output variable $T_{E e}$ includes the additional linguistic label "medium", as presented in Figure $1 \mathrm{~b}$.
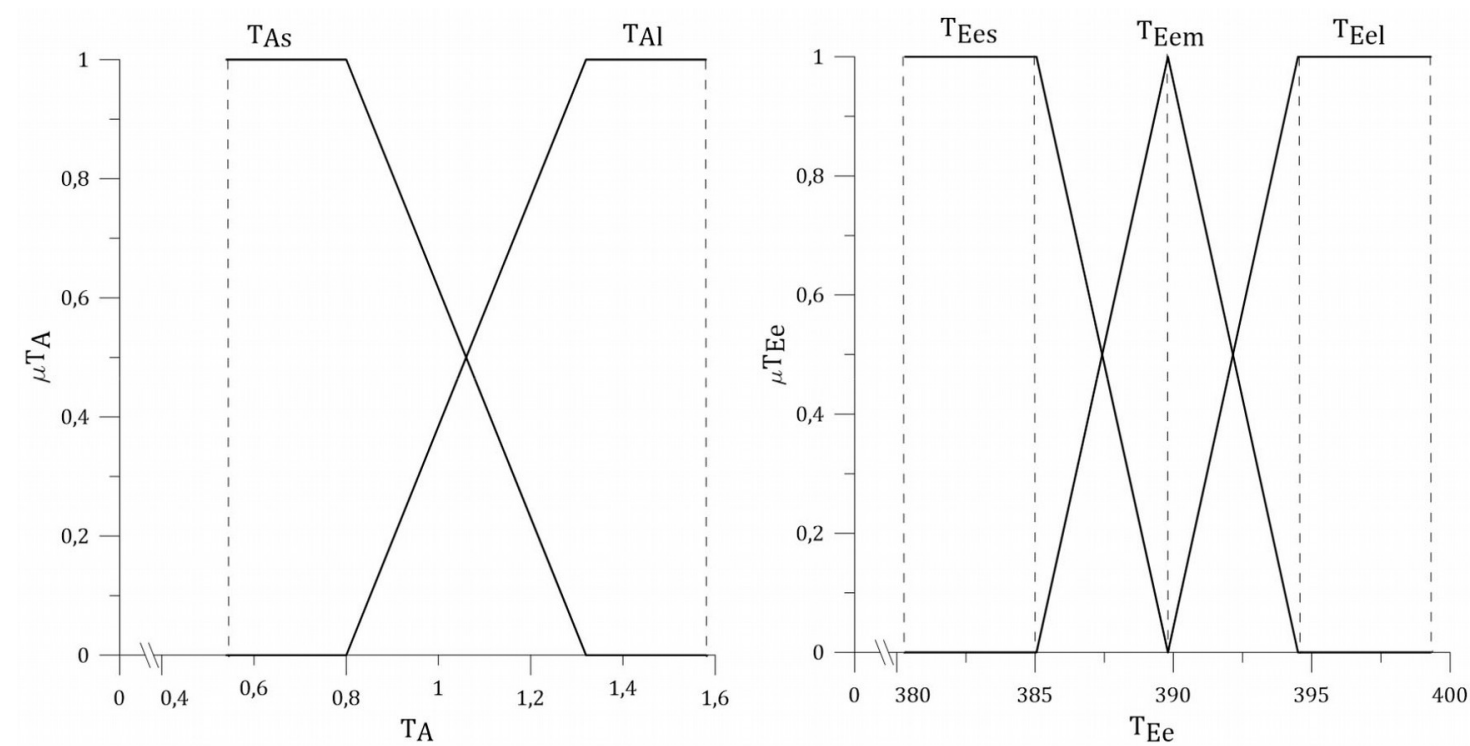

Figure 1. a) Fuzzy representation of $T_{A}$. b) Fuzzy representation of $T_{E e}$

The fuzzy model proposed to estimate standard times for assembling the twelve models of bicycles is composed of linguistic statements as those described in (28). For illustrative purposes, Table 18 contains a simplified version of the model, consisting of 16 statements parameterized according to the universes of discourses of the input-output variables for each bicycle model. The complete model includes a larger number of statements.

Each row of Table 18 represents a statement of the global model. For example, the first and fifth rows of Table 18 are equivalent to the $(u)$ and $(y)$ statements expressed in (28). For illustrative purposes, Table 19 characterizes the values of the linguistic labels for the output variable " $T_{E e}$ " in the assembly lines of the bicycle $1 \mathrm{~A}$ and the bicycle $1 \mathrm{~B}$. 


\begin{tabular}{|c|c|c|c|c|c|c|c|c|c|c|}
\hline$T_{A}$ & $T_{B}$ & $T_{C}$ & $T_{D}$ & $T_{E}$ & $T_{F}$ & $T_{G}$ & $T_{H}$ & $T_{I}$ & $T_{J}$ & $T_{E c}$ \\
\hline$T_{A s}$ & $T_{B s}$ & $T_{G s}$ & $T_{D s}$ & $T_{E s}$ & $T_{F s}$ & $T_{G s}$ & $T_{H s}$ & $T_{I s}$ & $T_{J s}$ & $T_{E e s}$ \\
\hline$T_{A s}$ & $T_{B s}$ & $T_{C s}$ & $T_{D s}$ & $T_{E s}$ & $T_{F s}$ & $T_{G s}$ & $T_{H l}$ & $T_{I l}$ & $T_{J l}$ & $T_{E e l}$ \\
\hline$T_{A s}$ & $T_{B s}$ & $T_{G s}$ & $T_{D s}$ & $T_{E s}$ & $T_{F s}$ & $T_{G s}$ & $T_{H s}$ & $T_{I l}$ & $T_{J l}$ & $T_{E e s}$ \\
\hline$T_{A s}$ & $T_{B s}$ & $T_{G s}$ & $T_{D s}$ & $T_{E s}$ & $T_{F s}$ & $T_{G s}$ & $T_{H s}$ & $T_{I s}$ & $T_{J l}$ & $T_{E e s}$ \\
\hline$T_{A l}$ & $T_{B l}$ & $T_{C l}$ & $T_{D l}$ & $T_{E l}$ & $T_{F l}$ & $T_{G l}$ & $T_{H l}$ & $T_{I l}$ & $T_{J l}$ & $T_{E e l}$ \\
\hline$T_{A l}$ & $T_{B l}$ & $T_{C l}$ & $T_{D l}$ & $T_{E l}$ & $T_{F l}$ & $T_{G l}$ & $T_{H s}$ & $T_{I s}$ & $T_{J s}$ & $T_{E e l}$ \\
\hline$T_{A l}$ & $T_{B l}$ & $T_{C l}$ & $T_{D l}$ & $T_{E l}$ & $T_{F l}$ & $T_{G l}$ & $T_{H l}$ & $T_{I s}$ & $T_{J s}$ & $T_{E e l}$ \\
\hline$T_{A l}$ & $T_{B l}$ & $T_{C l}$ & $T_{D l}$ & $T_{E l}$ & $T_{F l}$ & $T_{G l}$ & $T_{H l}$ & $T_{I l}$ & $T_{J s}$ & $T_{E e l}$ \\
\hline$T_{A l}$ & $T_{B l}$ & $T_{C l}$ & $T_{D l}$ & $T_{E} l$ & $T_{F s}$ & $T_{G s}$ & $T_{H s}$ & $T_{I s}$ & $T_{J s}$ & $T_{E e m l}$ \\
\hline$T_{A s}$ & $T_{B s}$ & $T_{G s}$ & $T_{D s}$ & $T_{E s}$ & $T_{F l}$ & $T_{G l}$ & $T_{H l}$ & $T_{I l}$ & $T_{J l}$ & $T_{E e m}$ \\
\hline$T_{A s}$ & $T_{B s}$ & $T_{C s}$ & $T_{D l}$ & $T_{E l}$ & $T_{F l}$ & $T_{G l}$ & $T_{H l}$ & $T_{I s}$ & $T_{J s}$ & $T_{E e m}$ \\
\hline$T_{A l}$ & $T_{B l}$ & $T_{C l}$ & $T_{D s}$ & $T_{E s}$ & $T_{F s}$ & $T_{G s}$ & $T_{H s}$ & $T_{I l}$ & $T_{J l}$ & $T_{E e m}$ \\
\hline$T_{A l}$ & $T_{B l}$ & $T_{C s}$ & $T_{D s}$ & $T_{E l}$ & $T_{F s}$ & $T_{G l}$ & $T_{H l}$ & $T_{I s}$ & $T_{J s}$ & $T_{E e m l}$ \\
\hline$T_{A s}$ & $T_{B s}$ & $T_{C l}$ & $T_{D l}$ & $T_{E s}$ & $T_{F s}$ & $T_{G s}$ & $T_{H s}$ & $T_{I l}$ & $T_{J l}$ & $T_{E e m}$ \\
\hline$T_{A s}$ & $T_{B s}$ & $T_{G s}$ & $T_{D s}$ & $T_{E l}$ & $T_{F l}$ & $T_{G s}$ & $T_{H s}$ & $T_{I s}$ & $T_{J s}$ & $T_{E e s}$ \\
\hline$T_{A l}$ & $T_{B l}$ & $T_{C l}$ & $T_{D l}$ & $T_{E s}$ & $T_{F s}$ & $T_{G l}$ & $T_{H l}$ & $T_{I l}$ & $T_{J l}$ & $T_{E e l}$ \\
\hline
\end{tabular}

Table 18. Linguistic statements of the fuzzy logic model

\begin{tabular}{|c|c|c|c|}
\hline Model & $\boldsymbol{T}_{\text {Ees }}$ & $\boldsymbol{T}_{\text {Eem }}$ & $\boldsymbol{T}_{\text {Eel }}$ \\
\hline 1A & $(380.3385 .05389 .8)$ & $(385.05389 .8394 .5)$ & $(389.8394 .5399 .3)$ \\
\hline 2A & $(323.6327 .30331 .1)$ & $(327.30331 .1334 .8)$ & $(331.1334 .8338 .6)$ \\
\hline
\end{tabular}

Table 19. Values of the linguistic labels for $T_{E e}$ for two bicycle models

To verify the approximation capabilities of the model, time measurements of the ten sub-processes, under nominal operating conditions, were obtained per bicycle model. Each set of measurements corresponds to an input to the fuzzy logic model. Table 20 presents samples of time measurement sets for two bicycle models, whereas Table 21 shows the results of standard times estimated by the fuzzy logic model.

\begin{tabular}{|c|r|r|r|r|r|r|r|r|r|r|}
\hline \multirow{2}{*}{ Model } & \multicolumn{10}{|c|}{ Time measurement per sub-process (min.s) } \\
\cline { 2 - 12 } & \multicolumn{1}{c|}{ A } & \multicolumn{1}{c|}{ B } & \multicolumn{1}{c|}{ C } & \multicolumn{1}{c|}{ D } & \multicolumn{1}{c|}{ E } & \multicolumn{1}{c|}{ F } & \multicolumn{1}{c|}{ G } & H & I & J \\
\hline 1A & 1.05 & 2.10 & 7.12 & 158.3 & 1.85 & 2.32 & 0.54 & 0.93 & 5.05 & 0.18 \\
\hline 2A & 0.25 & 1.18 & 16.50 & 99.3 & 3.52 & 6.71 & 0.94 & 3.25 & 5.54 & 0.38 \\
\hline
\end{tabular}

Table 20. Sets of time measurements per sub-process, for two bicycle models

\begin{tabular}{|c|c|c|c|r|r|r|r|r|r|r|r|r|}
\hline & \multicolumn{10}{|c|}{ Bicycle model } \\
\cline { 2 - 12 } & 1A & 1B & 2A & 3A & 3B & 3C & 3D & 3E & 3F & $3 \mathbf{G}$ & $3 \mathbf{H}$ & 4A \\
\hline $\begin{array}{c}\text { Standard time } \\
\text { estimated } \\
T_{E \text { e }} \text { (min) }\end{array}$ & 385 & 327 & 378 & 421 & 462 & 412 & 465 & 385 & 528 & 528 & 436 & 328 \\
\hline
\end{tabular}

Table 21. Standard times estimated for bicycle models 


\section{Results Analysis}

In the motorcycle's assembly case, the study allowed constructing seven linear regression models to estimate standard times for assembling the front parts, and seven linear regression models to predict standard times for the rear parts of the different motorcycle types (See Table 7 and Table 8). The selection of the variables for the construction of linear regression models took into consideration factors closely related to productivity, such as lighting and noise in the work environment, as well as age, weight, and height of the workers (see Table 1). The work included validation of the models constructed in terms of comparing the values of standard times estimated with measured values using the conventional chronometer methodology, obtaining results with errors that, in no case exceeded 10\%. Different from the chronometer methodology, the linear regression models allow estimating standard times directly, without resorting to new measurements, when there occur changes in the operating conditions of the assembly lines.

Regarding the case studies of assembling TV sets and PCBs, the study considered the construction of nonlinear optimization models that allow making appropriate predictions of the standard times in their assembly lines. For the TV sets case, the variables included in the mathematical models contemplated factors that directly affect the standard times. These variables are the product of the Westinghouse rating and the number of screws used in curved screen televisions $\left(X_{1}\right)$, the product of the Westinghouse rating and the number of screws used in flat-screen televisions $\left(X_{2}\right)$, and the product of the Supplements and the number of operators in the assembly line $\left(X_{3}\right)$. Analogously, for the PCBs case, the variables interrelated were the sum of Westinghouse ratings for the processes of packaging and storage in the automatic line $\left(X_{1}\right)$, and the sum of Supplements for the processes packaging, quality testing, and storage in the semiautomatic line $\left(X_{3}\right)$. The presence of differentiating characteristics within the assembly lines, both for TV sets and PCBs, was tackled with the construction of non-linear models, which allowed amalgamating their particular features with the appropriate estimation of their standard times. It is important to mention that in these two case studies, the construction of the mathematical models did not take into account the "set up" times, which affect the final values of standard times.

Figure 2 includes graphical comparisons between the results of standard times using the conventional chronometer method vs. those obtained with the proposed non-linear optimization model, both for the cases of assembling TV sets (Figure 2a) and PCBs (Figure 2b).

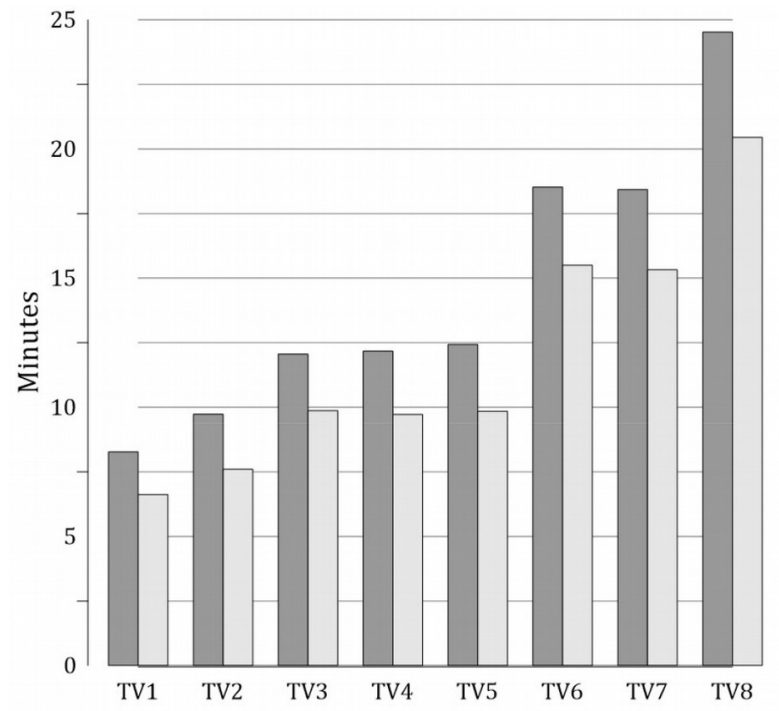

a) TV Models

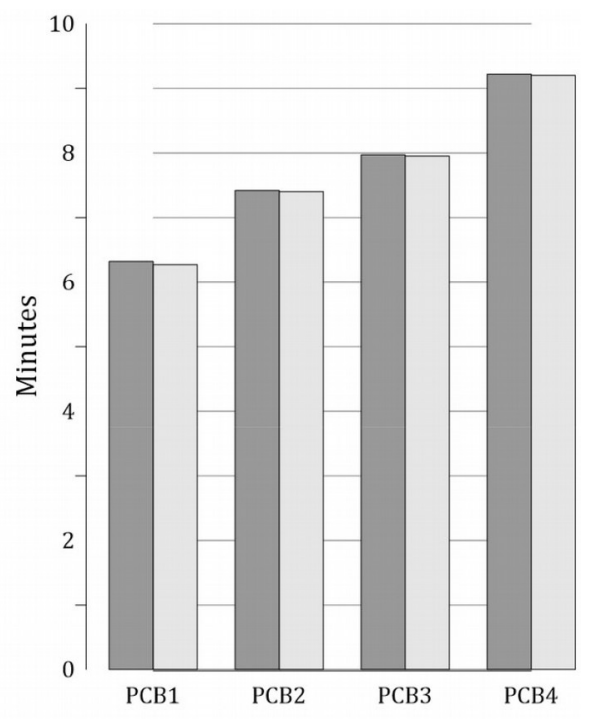

b) PCB Models

$\mathrm{T}_{\mathrm{s}}$ $\mathrm{T}_{\mathrm{Ee}}$

Figure 2. Comparison of standard times using the conventional chronometer method and the nonlinear optimization model.

a) TV case, b) Printed circuit boards case 
Finally, for the bicycle assembly case study using fuzzy logic models, the input variables to the models were the minimum and maximum times measured in the ten sub-processes inherent to the assembly lines and, as an output variable, the standard time estimated of the process. Different from the case of TV sets and PCB case, the interval between minimum and maximum times did consider the "set up" and dead times in the sub-processes. The fuzzification of the input variables used two linguistic labels with trapezoidal membership functions. In comparison, the fuzzification of the output variable considered three linguistic labels, with trapezoidal and triangular membership functions. In this study, the knowledge base consisted of 16 linguistic statements of the Mamdani type. This modeling approach can be extended to a variety of assembly processes.

For validation purposes, the fuzzy model used a single time measurement of the ten sub-processes, per bicycle model (see Table 20). The set of measurements served as input to the fuzzy model, to provide the results reported in Table 21. The differences between these results vs. those reported in Table 17, using the chronometer method, are within $6.2 \%$.

\section{Discussion and Conclusions}

The setting of standard times in assembly lines is a technique that, together with the measurement of work, allows determining optimal times to operate processes, minimizing the amount of work, eliminating unnecessary movements, and substituting methods; thus, facilitating the detection and reduction of unproductive times to generate a significant benefit.

Linear regression models are widely used for representing knowledge in many manufacturing processes; however, there is no reference on its uses for the prediction of standard times in assembly lines. There are advanced techniques for calculating standard times, such as the determined times, based on values stored in a database, or the well-known chronometer method. The construction of linear regression models such as those proposed in this paper is a reliable option that is easy to implement and useful to support decision-making related to increasing productivity. Specifically, the models constructed allowed the detection of activities that do not add any value within the production processes, such as transport and storage. This modelling approach is extendable to other scenarios, such as sales prediction, and personnel rotation rate, among other applications.

The option of constructing models to amalgamate in a single mathematical structure the estimation of standard times, for assembling TV sets or PCBs, led to the formulation of nonlinear optimization models, subjected to restrictions. Equations (20) to (25) describe the structure of the model. It is important to note that the restrictions imposed for optimizing the model lead to estimates of standard times smaller than the calculated by the chronometer method, for example, with non-zero estimation error.

The imprecision and uncertainty associated with empirical observations and incomplete information about processes can be appropriately handled using the unified framework that provides the fuzzy logic. In the bicycle assembly case, a fuzzy Mamdani model was proposed, which took into account measurements of minimum and maximum times of the assembly sub-processes. This way, the resulting intervals included process dead times and set up times. For the assembly lines of a bicycle model, there was a parameterized fuzzy model, and its performance in the determination of the standard time estimated was verified using a time measurement of the ten assembly sub-processes.

The veracity of the collected data plays an important role with respect to the simulations, since the results are affected by having unreliable data or average data between optimistic and pessimistic values. The subjectivity of the interviewee is another limitation for the simulation of processes using the modeling tool. To neutralize the aforementioned limitations, when starting the construction of the model, it is important to carry out planning together with experts, as a basis for the study. As for the subjectivity of the interviewees, it is possible to neutralize it by means of continuous monitoring of the entire working day to confirm or discard the information obtained. The proposed mathematical models can be a powerful tool for future projects, aimed at increasing performance and production based on incentives. This is achieved by setting a standard time and making a time control to several operators who perform the same activity during the work schedule for several days, and then adjust the target time and increase the production volume. 


\section{Acknowledgment}

This study is part of the research project "Modelo de gestión para la optimización de procesos y costos en la Industria de Ensamblaje," supported by the Research Department of the University of Cuenca (DIUC). The authors gratefully acknowledge the contributions and feedback provided by the IMAGINE Project team.

\section{Declaration of Conflicting Interests}

The authors declared no potential conflicts of interest with respect to the research, authorship, and/or publication of this article.

\section{Funding}

The authors received no financial support for the research, authorship, and/or publication of this article.

\section{References}

Abdelkhak, M., Salama, S., \& Eltawil, A.B. (2018). Improving Efficiency of TV PCB Assembly Line Using a Discrete Event Simulation Approach: A Case Study. Proceedings of the 10th International Conference on Computer Modeling and Simulation, 211-215. https://doi.org/10.1145/3177457.3177495

Al-Saleh, K.S. (2011). Productivity improvement of a motor vehicle inspection station using motion and time study techniques. Journal of King Saud University - Engineering Sciences, 23(1), 33-41.

https://doi.org/10.1016/j.jksues.2010.01.001

Bon, A.T., \& Daim, D. (2010). Time Motion Study in Determination of Time Standard in Manpower Process. Proceedings of the 3rd Engineering Conference on Advancement in Mechanical and Manufacturing for Sustainable Environment (1-6). Kuching, Sarawak, Malaysia.

Chandra, V.P. (2007). An Effort To Apply Work and Time Study Techniques in a Manufacturing Unit for Enhancing Productivity. International Journal of Innovative Research in Science, Engineering and Technology (ISO Certified Organization), 3297(8), 4050-4058.

Chauhan, K.A., Kumar, A., \& Shah, J.B. (2017). Maynard Operation and Sequence Technique (MOST) Intervention for Productivity Improvement of Manufacturing Process-A Review, 4(3), 24-26.

Elnekave, M., \& Gilad, I. (2006). Rapid video-based analysis system for advanced work measurement. International Journal of Production Research, 44(2), 271-290. https://doi.org/10.1080/00207540500160920

Freivalds, A., \& Niebel, B. (2013). Niebel's Methods, Standards, \& Work Design (13th ed.). McGraw-Hill Higher Education.

Garibaldi, J.M., \& Ozen, T., (2007). Uncertain fuzzy reasoning: A case study in modelling expert decision making, IEEE Transactions on Fuz:ay Systems, 15(1), 16-30. https://doi.org/10.1109/TFUZZ.2006.889755

Guerrero, P., Guaman, R., Colina Morles, E., \& Siguenza-Guzman, L. (2020). Optimization model for the estimation of standard times in the assembly industry. RISTI (Iberian Journal of Information Systems and Technologies), E37, 231-245.

Heizer, J., Render, B., \& Munson, C. (2016). Principles of operations management: Sustainability and supply chain management. Pearson Higher Ed.

Hendrich, A., Chow, M.P., Skierczynski, B.A., \& Lu, Z. (2008). A 36-hospital time and motion study: How do medical-surgical nurses spend their time? The Permanente Journal, 12(3), 25-34. https://doi.org/10.7812/TPP/08-021

Kulkarni, P.P., Kshire, S.S., \& Chandratre, K.V. (2015). Productivity Improvement Through Lean Deployment \& Work Study Methods. International Journal of Research in Engineering and Technology, 03(02), 429-434. https://doi.org/10.15623/ijret.2014.0302076

Marri, H.B., \& Shaikh, G.Y. (2012). The Role of Productivity Improvement Tools and Techniques in the Textile Sector during Manufacturing. Proceedings of the International Conference on Industrial Engineering and Operations Management (2570-2573), Istanbul, Turkey. 
Maynard, H.B., \& Hodson, W.K. (1992). Maynard's Industrial Engineering Handbook. McGraw-Hill.

Meyers, F.E. (1992). Motion and time study: Improving work methods and management. Prentice Hall.

Meyers, F.E., \& Stewart, J.R. (2001). Motion and Time Study for Lean Manufacturing (3rd ed.). Upper Saddle River, N.J: Pearson.

Montgomery, D.C., Peck, E.A., \& Vining, G.G. (2013). Introduction to Linear Regression Analysis. John Wiley \& Sons.

Moore, D., \& McCabe, G.P. (1998). Introduction to the Practice of Statistics (3rd ed.). New York: W. H. Freeman.

Morillas Raya, A. (2014). Introducción al análisis de datos difusos (1-64). Universidad de Málaga. España.

Mundel, M.E. (1970). Motion and time study: Principles and practices. Prentice-Hall.

Munyai, T.T., Mbonyane, B.L., Mbohwa, C., Mbonyane, B.L., \& Mbohwa, C. (2017). Productivity Improvement in Manufacturing SMEs: Application of Work Study Techniques. New York: Productivity Press. https://doi.org/10.4324/9781315180311

Nallusamy, S., \& Muthamizhmaran, S. (2015). Enhancement of Productivity and Overall Equipment Efficiency Using Time and Motion Study Technique-A Review. Advanced Engineering Forum, 14, 59-66.

https://doi.org/10.4028/www.scientific.net/AEF.14.59

Patel, N. (2015). Reduction in product cycle time in bearing manufacturing company. International Journal of Engineering Research and General Science, 3(3), 466-471.

Ramirez, J., Guaman, R., Colina-Morles, E., \& Siguenza-Guzman, L. (2020). Prediction of standard times in assembly lines using least squares in multivariable linear models. Applied Technologies, 195, 455-466. Springer International Publishing. https://doi.org/10.1007/978-3-030-42531-9_36

Rodas, P., Guaman, R., Colina Morles, E., Peña, M., \& Siguenza-Guzman, L. (2019). Mathematical model based on linear programming and fuzzy logic for time prediction in bicycle assembly industries. RISTI (Iberian Journal of Information Systems and Technologies), E19, 581-594.

Silva, C.W. de. (2018). Intelligent Control: Fuzæy Logic Applications. CRC Press. https://doi.org/10.1201/9780203750513

Shalley, C.E., \& Gilson, L.L. (2017). Creativity and the Management of Technology: Balancing Creativity and Standardization. Production and Operations Management, 26(4), 605-616. https://doi.org/10.1111/poms.12639

Turner, J. R., \& Thayer, J. (2001). Introduction to Analysis of Variance: Design, Analyis \& Interpretation: Design, Analyis \& Interpretation. SAGE Publications.

Yazdi, P.G., Azizi, A., \& Hashemipour, M. (2019). A hybrid methodology for validation of optimization solutions effects on manufacturing sustainability with time study and simulation approach for SMEs. Sustainability (Switzerland), 11(5). https://doi.org/10.3390/su11051454

Zohoori, B., Verbraeck, A., Bagherpour, M., \& Khakdaman, M. (2019). Monitoring production time and cost performance by combining earned value analysis and adaptive fuzzy control. Computers \& Industrial Engineering, 127, 805-821. https://doi.org/10.1016/j.cie.2018.11.019

Journal of Industrial Engineering and Management, 2021 (www.jiem.org)

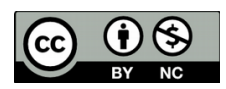

Article's contents are provided on an Attribution-Non Commercial 4.0 Creative commons International License. Readers are allowed to copy, distribute and communicate article's contents, provided the author's and Journal of Industrial Engineering and Management's names are included. It must not be used for commercial purposes. To see the complete license contents, please visit https://creativecommons.org/licenses/by-nc/4.0/. 